\title{
Adapting the Medium: Dynamics of Intermedial Adaptation in Contemporary Japanese Popular Visual Culture
}

\author{
Beáta Pusztai \\ Eötvös Loránd University (Hungary) \\ E-mail: stannoone@gmail.com
}

\begin{abstract}
With respect to adaptation studies, contemporary Japanese popular culture signifies a unique case, as different types of media (be those textual, auditive, visual or audio-visual) are tightly intertwined through the "recycling" of successful characters and stories. As a result, a neatly woven net of intermedial adaptations has been formed - the core of this complex system being the manga-anime-live-action film "adaptational triangle." On the one hand, the paper addresses the interplay of the various factors by which the very existence of this network is made possible, such as the distinctive cultural attitude to "originality," the structure of the comics, animation and film industries, and finally, the role of fictitious genealogies of both traditional and contemporary media in the negotiation of national identity. On the other hand, the essay also considers some of the most significant thematic, narrative, and stylistic effects this close interconnectedness has on the individual medium. Special attention is being paid to the nascent trend of merging the adaptive medium with that of the original story (viewing adaptation as integration), apparent in contemporary manga-based liveaction comedies, as the extreme case of intermedial adaptation. That is, when the aim of the adaptational process is no longer the transposition of the story but the adaptation (i.e. the incorporation) of the medium itself elevating certain medium-specific devices into transmedial phenomena.
\end{abstract}

Keywords: Japanese animation, intermediality, manga-anime-live-action film adaptational triangle, national identity.

"We will become an animation that transcends animation. [...] By showing mannequins while talking for thirty minutes, we will present you with a truly surreal world of animation." In a five-minute-long "pseudo-live-action” adaptation of the Silver Soul comics (Gintama, Hideaki Sorachi, 2003-) presented at the beginning of episode 165 of the eponymous animation series (Gintama, Yōichi 
Fujita-Shinji Takamatsu, 2006-2010), the creators are trying to negotiate the boundaries of the animated medium [Figs. 1-2]. Designating their project as a liveaction adaptation and applying photographic depiction to an objectively existing space, on the one hand, they build a bridge between animated and live-action film. On the other hand, the series of still photographs inserted into the equally static, yet actual motion picture footage evoke the static and timeless nature of the panels found in a comic book. Thus, the film reflects on the widespread notion that anime (the Japanese cartoon) is nothing more than "a manga (comic book) set into motion." "Furthermore, the replacement of flesh-and-blood actors and actresses with mannequins (that is to say, life-sized humanoid puppets) draws on another kind of animation technique besides the traditional cel animated cartoon - that of puppet animation, or stop-motion animation in general. Although the film does resemble all three of the earlier mentioned media (live-action film, comics and animation), it belongs to none of those. While photographic depiction may be a necessary condition for a live-action film, it does not appear to be a sufficient one. Nevertheless, the fact that the film does not aim for an illusion of continuous character and/or camera movement, questions whether it can actually qualify as an animated piece of work. Not exactly "live-acted," but not "decently animated" either, this short segment of Silver Soul contemplates the ontological-technological question of how and at what point does a sequence of still pictures become a full-fledged animated sequence (or motion picture in general). Correspondingly, it comments upon and takes to the extreme a current phenomenon in contemporary popular culture in Japan, that of the powerful synergy among the various media platforms, be those textual, auditive, visual or audio-visual, analogue or digital, narrative or non-narrative.

The present essay aims to delineate some of the most significant characteristics of this tightly woven intermedial network of adaptations, starting with its fundamental cultural and industrial prerequisites, and subsequently to discuss the effects this close interconnectedness has had on the aesthetics of the individual medium. I will focus on the core of this complex system, the mangaanime-live-action film "adaptational triangle" as the most frequent combination and order of popular visual media, and as steps of an intermedial adaptational

1 The accounts of Craig Norris (Norris 2009) and Robin E. Brenner (Brenner 2007) of the history of the manga and anime media, and the ordering of the chapters from the history of manga to the development of anime in the volume Japanese Visual Culture (MacWilliams 2008), all allude to the perception of the two media having been closely intertwined throughout their histories, with manga acknowledged as "the origin" (Norris 2009, 236), one of the many predecessors of anime. 
process. These particular media are linked together in both creative and business thinking. Most television and video anime series are adapted from manga or video games, a tendency founded by Osamu Tezuka, one of the most prominent pioneers of "terebi-anime" (television cartoon), and his 1963 show, Astro Boy (Tetsuwan Atom). Then again, in each and every anime (and manga), there lies the promise of a potential live-action version. For instance, the stories and characters of Paradise Kiss (Ai Yazawa, 1999-2003), Gokusen (Kozueko Morimoto, 20002007), Ouran High School Host Club (Bisco Hatori, 2003-2010) and Death Note (Tsugumi Ōba-Takeshi Obata, 2003-2006) comics have all went down the path of turning first into an anime, then a live-action film or series. Conversely, the success of a manga-turned-live-action film (series) has the power to urge the production of an anime adaptation, as in the cases of Mischievous Kiss (Itazura na Kiss anime: Osamu Yamasaki, 2008) and Lovely Complex (anime: Kōnosuke Uda, 2007). Other media, such as video/DVD releases, drama-CD's, video/PC games, literature (light novels especially), merchandising (figurines, wallpapers and original art albums) and fan events - like the manga/anime conventions and costume plays ("con" and "cosplay," for short) - are always welcome to enter into this intermedial playground and mingle with the manga-anime-live-action group. The interplay and interdependence of so many medial agents presupposes a unique industrial structure and specific cultural practices.

Firstly, the large sizes of the comic (Sugimoto 2010), ${ }^{2}$ animation (Norris 2009) ${ }^{3}$ and film industries (Kakeo 2010; MPAA 2012), ${ }^{4}$ and the consequent absence of a singular dominant visual medium on the market clearly motivates creative intermedia cooperation and competition. Also, the fan basis of each medium is broad enough to be of interest to the other two, providing them with "raw material." This holds true for the manga industry in particular. For most popular stories set out on their intermedial journeys as comics, the industry bears the power to determine

2 "In 2007, manga books and magazines comprised some 14 percent of all published titles in Japan. Manga publications' total circulation exceeds five hundred million, 69 percent of the total distribution of all publications combined" (Sugimoto 2010, 254). As an indication of the rapid growth of the manga industry during the 1990s and 2000s, it should be noted that a 2000 survey estimated manga's share of all publications in Japan to be around 40 percent (Sugimoto 2002, 249).

3 Norris designates the following statement as the single most important point in his summary of a 2005 survey, conducted by JETRO: "Japan is the largest provider of animation worldwide, with approximately 60 per cent of animation shown around the world made in Japan” (Norris 2009, 254).

4 In 2009, Kakeo estimates Japan's film industry to be the largest film industry in the world; while in 2012, the Motion Picture Association of America places Japan as number three (cf. The Guide to Japanese Film Industry \& Co-Production 2010). 
the current trends in visual media business as a whole. What makes manga so attractive in the eyes of its two allied media, apart from the endless supplies, is the generic and thematic diversity of products - as opposed to their American and most European counterparts, Japanese comics are targeting readers from all age groups, males and females alike; consequently, an age/gender based typology is usually preferred to the "Western-style" generic typology to categorize manga (magazines) and anime. In Japan, such popular mythologies or - in an intermedial-industrial sense - complex multimedia "supersystem[s] of entertainment" (Iwabuchi 2004, 63, cites Marsha Kinder) are not exlusively centered around action and adventure heroes, but the often mundane lives of average men and women also get their fair share; the imitation of which - as Frédéric Boilet aptly proposes in his Nouvelle Manga Manifesto (Boilet 2001) - could revolutionize and highten the volume of the comic industries of the Western world.

Secondly, the traditionally self-organized and self-sufficient structure of the Japanese film and animation industries is another key factor in the production of intermedial adaptations. The system centres around the so-called production committees (seisaku-iinkai), temporary and project-based formations of companies from different fields, with the production company at the heart. This production committee system can be considered a variation of the producer system, with the difference that the individual producer is rather a mere go-between, a mediator between the sponsors sitting in the committee and the creative team (or the Japanese and the overseas partner, in case of an international co-production), than an active angent as the leader of the committee - given that all major decisions require unanimous approval from all representatives of the committee (Kakeo 2010, 47). All the companies that provide the film/animation (series) any support in any of the stages of pre-production, production, post-production, or distribution, automatically become members of the committee. For example, if the production company is joined by a television station, a software development company and a magazine, then the advertizing in two media, the television broadcast and the production of a video game and other merchandise are guaranteed (Kakeo 2010, 46). Since the establishment of a committee is the prerequisite for starting the preparations for a film, gaining the help of potential sponsors is one of the creators' top priorities. As sponsors usually consider already successful stories as more secure, thus better investments than original screenplays, the practice of adapting popular manga persists (Cavallaro 2007, 7). This holds true especially in the case of straight-to-television productions (which means the majority of anime projects), where state funding is even less significant. 
Thirdly, the sense and value accorded to the idea of "originality" in the aesthetics of traditional arts and crafts in Japan is different from our contemporary "Western" concept. Perhaps, the difference lies in the fact that the practice of learning through imitation in a master - apprentice relationship has indured much longer in "the East." In such traditional occupations as kabuki and nō acting, tea ceremony (sadō), pottery or flower arrangement (kadō/ikebana), mastering the right skills and techniques of one's profession and executing them at the highest level possible is of higher value than individual innovation and the ambition of self-expression. Therefore, the adaptation or the remake is by no means perceived as simply a derivative of its original, but holds an equal artistic status.

Finally, intermediality plays a crucial part in the permanent negotiation of national identity, alongside the dichotomies of "East and West," "tradition versus modernity." ${ }^{5}$ On the one hand, the deliberate fusion of media serves as a means of legitimization through indigenization. Associating a new medium with traditional art forms has long been a strategy to transform things "foreign" into something essentially, that is historically Japanese. Let us observe some of the oldest names associated with the Japanese cartoon: senga-eiga ("line-drawing film”) connects anime to the medieval art of picture scroll painting (e-makimono) and to woodblock-printing (ukiyo-e), popular throughout the premodern times. Manga-eiga ("comics-film") - or simply manga - links anime to manga, which in turn, gains its legitimacy from having been named after Hokusai Katsushika's famous woodblock-print collection Hokusai Manga (Hu 2010, 101-102). Theorists, creators and businesspeople alike participate in the drawing up of such fictitious "genealogies" of media, in which the traditional legitimizes the modern, providing the viewer with a sense of historical continuity. Moreover, the legitimizing power proves to be contagious: just as manga (itself made legitim by the prestige of emakimono and ukiyo-e) is capable of legitimizing anime, anime can retroactively bestow the status of a legitimate art form upon utsushi-e ("reflected/projected pictures"), the Japanese version of laterna magica discovered at the millennium, by simply nicknaming it "Edo-anime." As for gestures of intermedial merging on the part of auteur filmmakers, one must mention Satoshi Kon's homage to woodblock-printing in his 2001 Millennium Actress (Sen'nen joyū), Takashi Murakami's more political Superflat movement (Lamarre 2006), the parades of shapeshifting raccoons - reminiscent of the procession of demons

$5 \quad$ Dani Cavallaro designates the modern Japanese state of mind of being torn between the bipolar opposites of East/tradition and West/progress as a kind of "cultural schizoidism" (Cavallaro 2013, 11). 
as depicted on many e-maki scrolls - in Isao Takahata's 1994 Studio Ghibli feature, Pom poko (Heisei tanuki gassen ponpoko), and Osamu Tezuka's 1970 masterpiece, Cleopatra, where the death scene of Caesar evokes both the kabuki theatre and the "superflat" aesthetics of woodblock-printing - again linking the present to the much idealized Edo era [Figs. 3-4]. In the popular sphere, one could take for example the recent television series Mononoke (Kenji Nakamura, 2007), Cool-Headed Hoozuki (Hōzuki no reitetsu, Hiro Kaburaki, 2014), Yami Shibai: Japanese Ghost Stories (Yamishibai, Tomoya Takashima, 2013), Chōyaku hyakunin isshu: Uta koi (Ken'ichi Kasai, 2012), and the elaborate and highly stimulating visuals of Dusk Maiden of Amnesia (Tasogare otome x Amnesia, Shin Ōnuma - Takashi Sakamoto, 2012). Although not systematically, such series as Natsume's Book of Friends (Natsume yūjinchō, Takahiro Ōmori 2008, 2009, 2011, 2012) and Kamisama Kiss (Kami-sama hajimemashita, Daichi Akitarō, 2012) occasionally revisit the style of traditional Japanese paintings.

The indigenous and the traditional, however, do not exist solely in opposition to the foreign and the modern, but might as well join them in the idea of the hybrid. Hybridity as a quality legitimizes its object as Japanese, traditional and nostalgic, while declaring it exotic, modern and fashionable at the same time which makes it appealing to an even wider range of target audience. For instance, the name anime - the most widely used denomination of Japanese cartoon - is an abbreviated form of animeeshon ("animation"), a word borrowed from English. Even smarter is the naming of the avantgarde animation project launched in 2006 by the longest-standing modern animation studio in Japan, Tōei Animation Studio, celebrating the $50^{\text {th }}$ anniversary of the studio's founding. The name $\mathrm{Ga}$ nime is a wordplay on "manga + anime," drawing on the historical prestige of two visual media already; next to which the project's slogan - "a modern-day version of a kami-shibai” (Tsukui 2006) - introduces a third one, namely, papertheatre (kamishibai), a contemporary to anime (and precursor of the serially formatted terebi-anime) that has its roots in the Edo-period storytelling sessions of Buddhist monks. Accordingly, the notions of the traditional and the hybrid make a viable marketing strategy.

Turning to the question of the aesthetic consequences of intermediality, while bearing hybridity in mind, I would argue that a new (or renewed) approach towards the adaptational process has appeared in contemporary Japanese popular media. In spite of attempting to "translate" the aesthetic devices of the source medium to the "language" of the recieving medium, this new trend of animated and especially live-action manga adaptations endeavour either to integrate or 
to imitate certain stylistic features characteristic to the source medium. In the case of a live-action adaptation, the integration of the source medium means the incorporation of drawn and/or animated elements into the "live" composition (such as the sketch-like backgrounds and atmospheric sound effects inserted in a text format seen in Switch Girl!! [Hiroki Hayama, 2011-2012] [Figs. 5-6]); while imitation would mean the "translation" of the graphic elements into their photographic equivalents. Nonetheless, sometimes there is a very fine dividing line between the two categories, which is primarily apparent in the dialogue between two graphic (e.g. comics and cartoon) or two photographic (e.g. photography and live-action film) media. These alternative approaches have brought about the transformation of certain medium-specific thematic, stylistic and structural devices into transmedial phenomena - ready at the disposal of virtually any of the media participating in the intermedial network. The circulation of these transmedial motives has foregrounded the problem of the adaptability of the medium as such. Adaptations are now preoccupied with adapting the medium along with, or even over the story, indicating a shift in the adaptational attitude from "adapting the story" to "adapting the medium."

When imitating the medium, the adaptation may either copy some of the stylistic instruments peculiar to its original, or apply to itself the formalstructural attributes of the source medium. Let us take the Paradise Kiss adaptational triangle as an example. The manga, the anime and the live-action feature versions alike, frequently deploy the manga-technique of inserting - often multiple - "external" establishing shots between two scenes [Figs. 7-16] (Pusztai 2012). These shots are external in a double sense: firstly, as opposed to the classic Hollywood establishing shot, they do not construct the space of action (that is, the spatial relations of the characters), but remain on the outside, building up the very environment in which the action takes place. Secondly, they usually feature the exterior of a building. What is more, they do not show us $a$ school or $a$ café, but any school or any café -the more schematic, the easier to recognize, the better. In our example, neither in the close-up of the heroine nor in the medium long shot of her sitting at her desk does the background indicate that the scene is set at a school. Thus, it is up to the two detailed external establishing shots at the beginning of the scene to draw up the setting. This convention of spacebuilding serves to counteract the inability of the so-called negative spaces (the homogenous, monochrome, usually white backgrounds) of the comic panel to efficiently orient the reader in space. Consequently, in the cases of the anime and live-action adaptations, the deployment of the very same device seems 
odd, unnatural even. Although a graphic medium, it is a standard practice in mainstream cel animation to fill in the elements of the background - rendering the external establishing shots of the manga unnecessary. In live-action film, these manga-inspired shots stand in an even starker contrast with the potentials of photographic depiction. The same could be said - to different degrees - about the application of constant voiceover narration channelling the "inner voices" of the heroes; the use of non- or semi-diegetic backgrounds reflecting the minute emotional states and swings of the characters and their relationships; the often theatrical execution of compositions and actor movement; and the frequent leaps back and forward between the various levels of the diegesis.

As for the imitation of the source medium's outward presentation, the narrative fragmentation of feature-length live-action manga/anime adaptations is a salient fashion in contemporary youth comedies (e.g. Thermae Romae [Hideki Takeuchi, 2012], Cromartie High School [Sakigake! Cromartie Kōkō, Yūdai Yamaguchi, 2005], Nodame Cantabile: Saishū gakushō zenpen [Hideki Takeuchi, 2009] and High School Debut [Kōkō Debut, Tsutomu Hanabusa, 2011]). Here, fragmented narration emerges as a result of the live-action adaptation taking upon itself the mediumspecific structure of the comic book devided into chapters - often with the help of typical manga-like devices, such as the external establishing shots serving as "cover pages" for each new "chapter." Levels of narrative fragmentation range from "mangaish," through cinematic and filmic, to self-reflective fragmentation (Pusztai 2013).

All the motives mentioned earlier can be traced back to the comic narration's essentially static and graphic nature, its lack of ability to construct an uninterrupted illusion of a coherent structure of space and of a realistic sensation of the flow of time (and thus, of movement). I would go on to argue that these aesthetic devices have been developed specifically in order to compensate for this lack of realism in comic depiction - the same kind of realism inherent in the cinematic, and fairly achievable in the animetic media. It is precisely this paradox of animated and especially live-action manga-adaptations using such redundant and unmotivated, thus emphatically artificial, "manga-flavoured" techniques - and the concurrent overshadowing of their own medium-specific features in favour of the now transmedial manga-devices - which makes the approach of adapting the medium bizarre by nature. Nonetheless, especially since the turn of the century, adaptations tend to make use of those either consciously (see the live-acted Lovely Complex) or unconsciously (see the live-acted Gokusen: The Movie). 
It is the tendency and the possible outcomes of the intentional merging of the various media platforms at the aesthetic level that the sequence from Silver Soul, addressed at the beginning of the paper, reflects upon - be it a disruptive force or a creative potential, complementing animation and live-action film's innate cinematism with the constructed "pseudo-cinematism" of the comic art. Having taken a closer look at the present state of affairs in the field of animated and live-action manga-adaptations, the idea of comics and live-action film joining forces in order to give birth to the ultimate form of "animation that transcends animation" does not seem so far-fetched anymore.

\section{References}

Boilet, Frédéric. 2001. Nouvelle Manga Manifesto. http://www.boilet.net/am/nouvellemanga_manifeste_1.html. Last accessed 20. 02. 2015.

Brenner, Robin E. 2007. Understanding Manga and Anime. Westport: Libraries Unlimited.

Cavallaro, Dani. 2007. Anime Intersections: Tradition and Innovation in Theme and Techniques. Jefferson and London: McFarland \& Company, Inc.

Cavallaro, Dani. 2013. Japanese Aesthetics and the Anime: The Influence of Tradition. Jefferson: McFarland \& Company, Inc.

Hu, Tze-Yue G. 2010. Frames of Anime: Culture and Image Building. Hong Kong: Hong Kong University Press.

Iwabuchi, Kōichi. 2004. How "Japanese” Is Pokémon? In Pikachu's Global Adventure: The Rise and Fall of Pokémon, ed. Joseph Tobin, 53-79. Durham and London: Duke University Press.

Kakeo, Yoshio. 2010. The Guide to Japanese Film Industry \& Co-Production 2010. http://unijapan.org/en/project/information/japan-film-industry-guide.html Last accessed 20. 02. 2015.

Lamarre, Thomas. 2006. The Multiplanar Image. In Mechademia I: Emerging Worlds of Anime and Manga, ed. Frenchy Lunning, 120-143. Minnesota: University of Minnesota Press.

MacWilliams, Mark W, ed. 2008. Japanese Visual Culture: Explorations in the World of Manga and Anime. New York: M.E. Sharpe, Inc. 
Motion Picture Association of America, Inc. 2012. Theatrical Market Statistics 2012.

http://www.mpaa.org/wp-content/uploads/2014/03/2012-Theatrical-MarketStatistics-Report.pdf. Last accessed 20. 02. 2015.

Norris, Craig. 2009. Manga, Anime and Visual Art Culture. In The Cambridge Companion to Modern Japanese Culture, ed. Joshio Sugimoto, 236-260. Cambridge: Cambridge University Press.

Pusztai, Beáta. 2012. Képregény + film = rajzfilm? A japán rajzfilm a médiumközi adaptáció hálójában. [Comics + Film = Cartoon? The Japanese Cartoon in the Network of Intermedial Adaptations], Apertúra. Film - Vizualitás - Elmélet. http://apertura.hu/2012/nyar/pusztai-kepregenyfilm=rajzfilm. Last accessed 20. 02.2015.

Pusztai, Beáta. 2013. Az egészestés mangafeldolgozások narratívájának töredezettsége. [Narrative Fragmentation in Feature-Length Live Action Manga Adaptations], Metropolis no. 01: 64-77.

Sugimoto, Yoshio. 2010 [1997]. An Introduction to Japanese Society. Cambridge: Cambridge University Press.

Tsukui, Mina. 2006. Ganime: The Art of Slow Animation. Yomiuri Shimbun 16. 09. 2006.

\section{List of Figures}

Figures 1-2. "Pseudo-live-action" adaptation of the Silver Soul comics and anime series, starring mannequins.
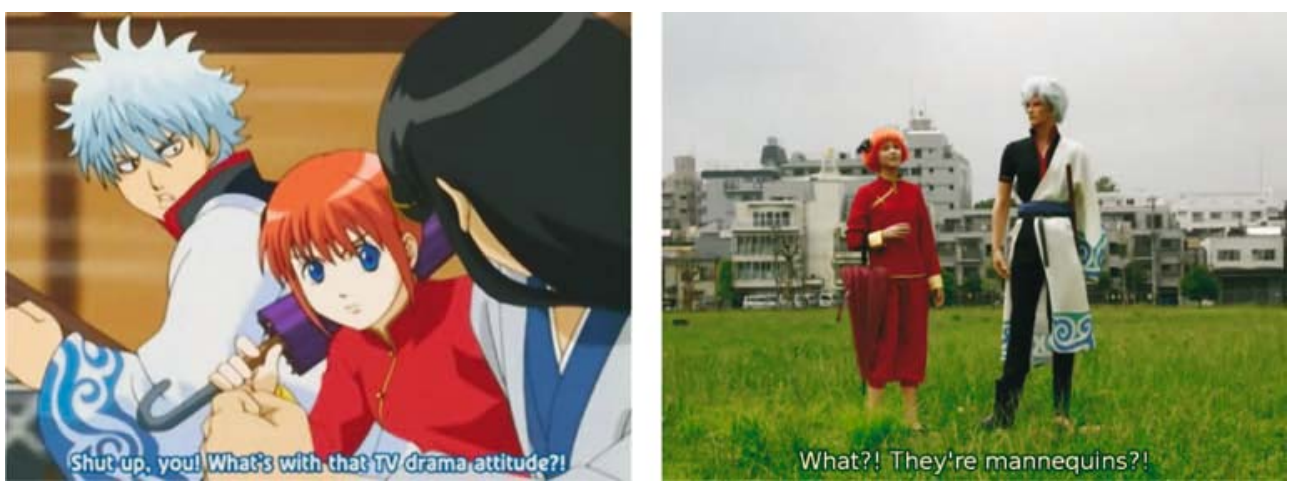
Figures 3-4. References to traditional Japanese arts in Millennium Actress and Cleopatra.
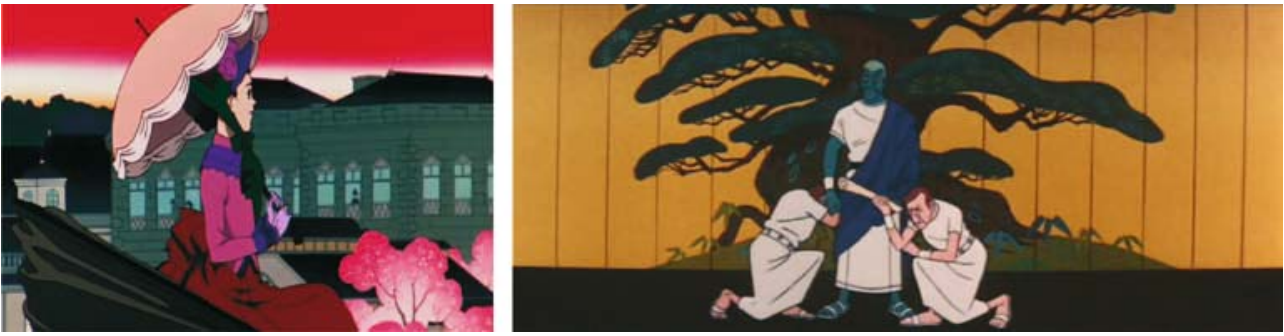

Figures 5-6. Adapting the medium 1: integration (Switch Girl!!).
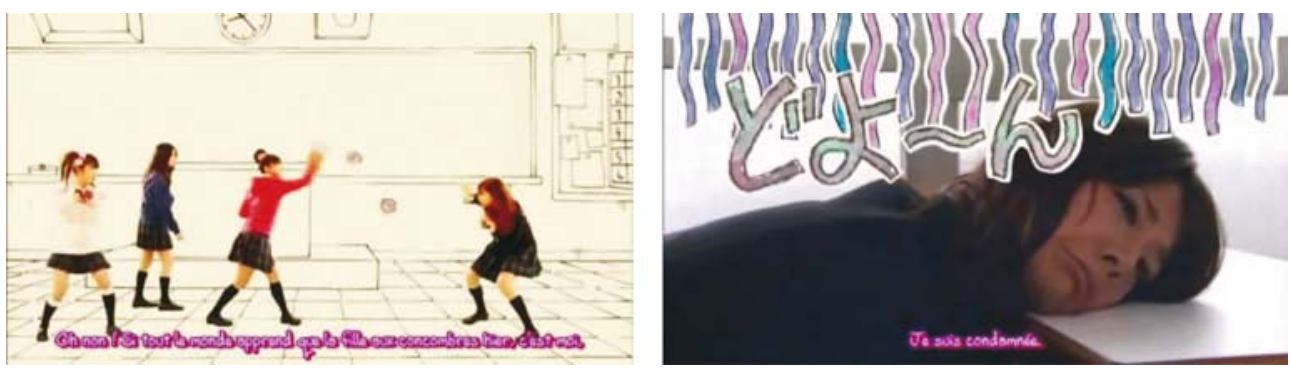

Figures 7-16. Adapting the medium 2: imitation of multiple external establishing shots (Paradise Kiss).
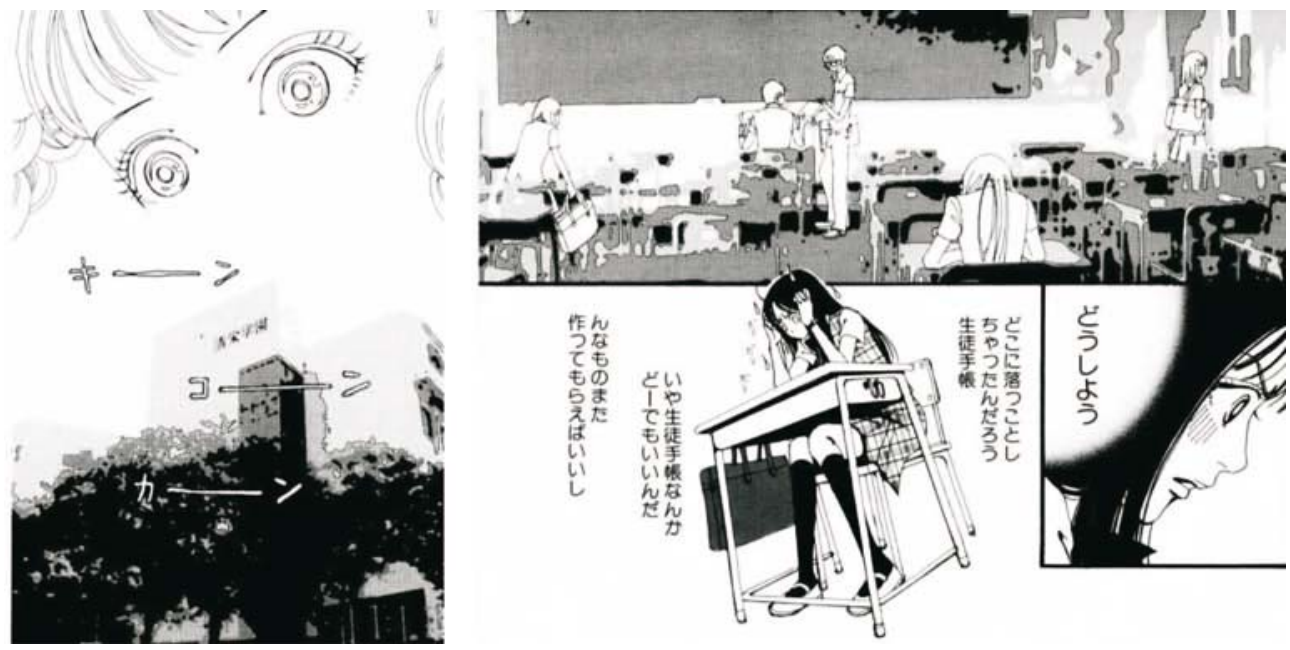

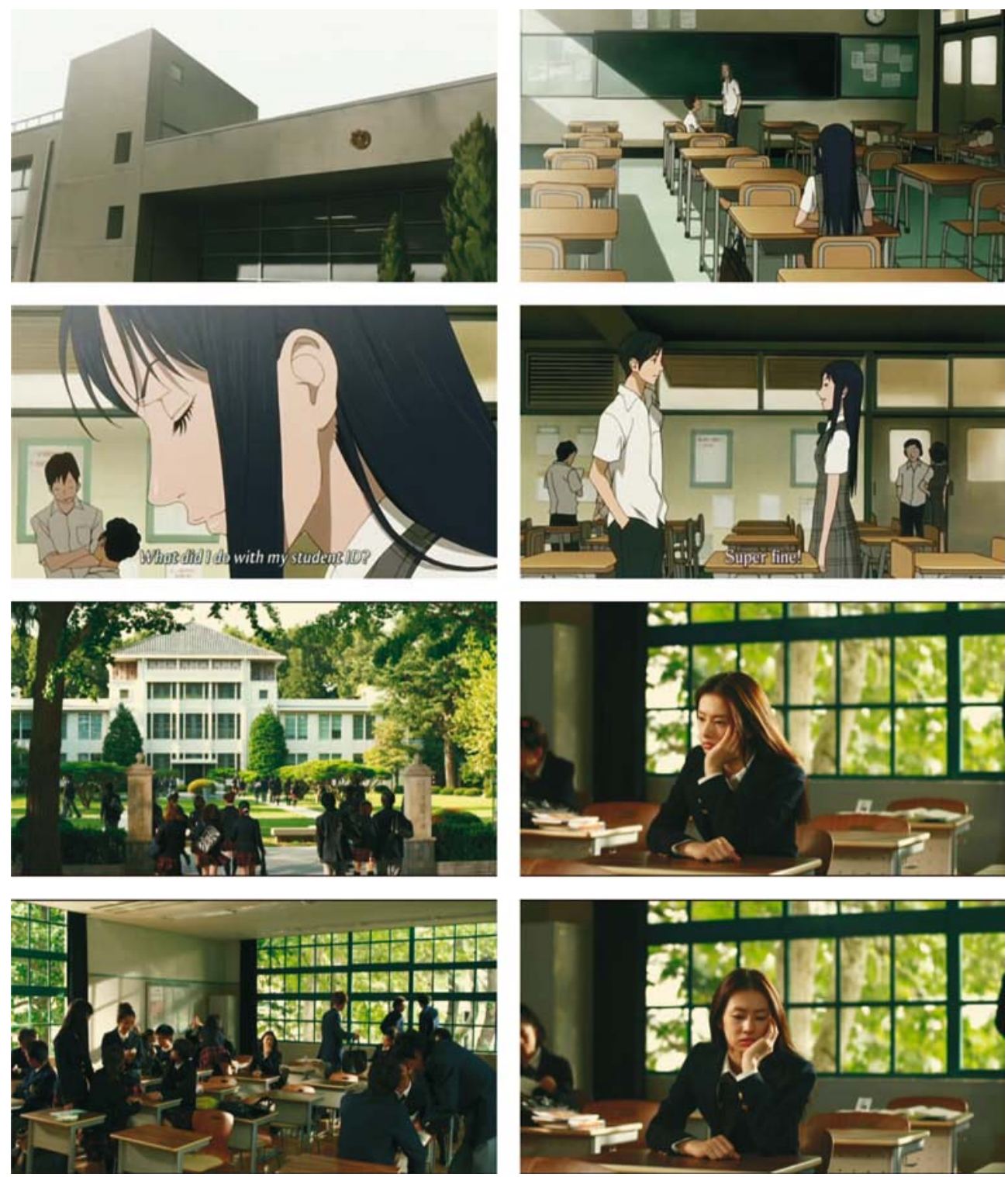